\title{
Supply Chain Integration Based on Core Manufacturing Enterprise
}

\author{
Wenqin $\mathrm{Cao}^{1}$ and Haiyan $\mathrm{Zhu}^{2}$ \\ ${ }^{1}$ School of Mechanical and Electronical Engineering, East China Jiaotong University, \\ Nanchang, P.R. China \\ ${ }^{2}$ School of Railway Tracks and Transportation, East China Jiaotong University, \\ Nanchang, P.R. China
}

\begin{abstract}
System integration solutions and model of supply chain are proposed based on core manufacturing companies, combining the actual operation of the supply chain process of a motor enterprise. The operation of the supply chain is discussed from the supplier integration, internal integration, and customer integration. The process integration is studied from the logistics integration, information flow integration and capital flow integration. Strategic decision management corresponding to cultural integration, separately discuss from the development strategic integration, concept integration and management integration.
\end{abstract}

Keywords: Supply chain (SC); Integration; Logistics; Core manufacturing enterprise.

\section{Introduction}

China is becoming a center of world manufacture, which is a good opportunity for the Chinese manufacturers [1]. The paper responses to the urgent needs of manufacturing enterprises, combining with personal experiences of $\mathrm{K}$ Company (a medium car manufacturer) integration, which is for manufacturing company's supply chain management [2-3]. The core manufacturer in the supply chain plays leading role in the integration process, relying on the superiority of their own capital, technology and brand to influence and integrate the upstream and downstream businesses from strategic level to plan and control layer [4-5].

\section{Prerequisite of the Core Manufacturing Supply Chain Integration}

For supply chain integration, the core manufacturing enterprise should have certain conditions to play leading role in the supply chain integration. Core business must have at least the following three conditions [6].

1). Perfect internal management information system. Business should have enterprise resource planning system Etc. to grasp all kinds of raw materials, semi 
finished goods inventory and shipments in order to promptly respond to market; should have good customer relationship management system to respond customer needs and personalized service. Therefore, the core business should have a more complete internal management information system to integrate internal resources and companies.

2). Smooth and efficient business processes. The business can achieve effective interface between the upstream and downstream enterprises with smooth and efficient business process. So business in the supply chain business process integration should be preceded by rationalization, optimization and reconstruction, the establishment of efficient standardization of business norms.

3). A sound management system and operating specifications. Different enterprise has different business processes and operations, which make a lot of inconvenience in communication. The core business should establish a unified management and operating standards, and information systems integration standards.

\section{Contents and Methods of Supply Chain Integration}

Based on core manufacturing companies, supply chain integration will be divided by the executive level into the strategic level integration, planning and control layer integration, basic layer integration. Strategic level integration includes development strategic integration, concept integration, management integration; planning and control layer includes logistics integration, process integration, information integration and capital flow integration; basic layer integration includes supplier integration, internal integration and customer integration. Integration model is shown in Figure 1.

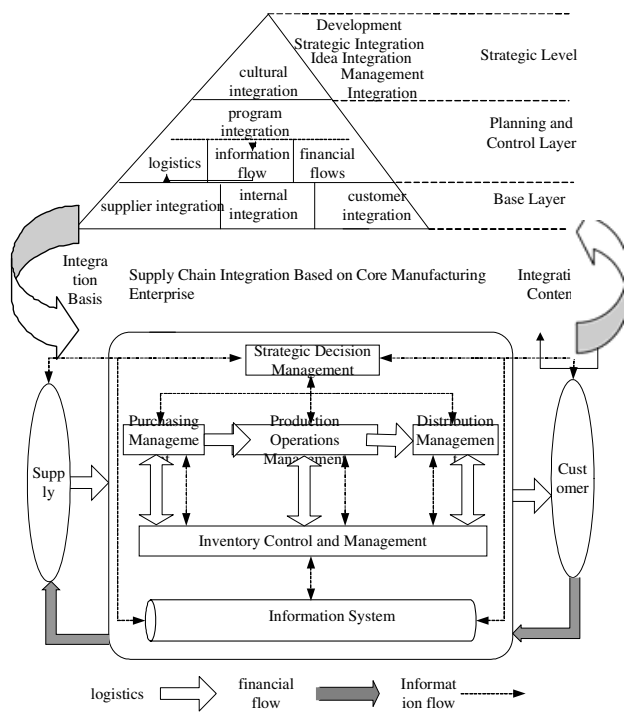

Fig. 1. The integration model of supply chain 


\subsection{Basic Layer Integration}

1. Internal Integration: Good internal integration is successful experience for other businesses in supply chain. Internal integration is divided into two levels: the internal process and information integration, organizational integration [7].

1) The internal process and information integration: Business should identify and optimize core business processes, establish standard operation procedures to improve the speed and quality of processes. Internal information of core business should be integrated by process to respond to market changes and customer demands.

2) Organizational integration: Organizational integration should enable organizational design, structure and operation to meet the system objectives, and establish processoriented management mode. Distributed logistics should be unified and integrated with procurement to set up an integrated logistics system, whose all logistics-related functions are unified.

2. Supplier integration Core business should have a good supplier management system, optimize supply chain structure from the number of suppliers, quality and other aspects in the global integration.

In the implementation of supplier integration process, business can start from the following areas.

1) Establish strategic partnership with key suppliers. Establishment of strategic partnership can strengthen procurement, and timely meet the needs of the supply chain to reduce supply chain inventories through JIT purchasing. At the same time, the core business should integrate design and research capabilities of supplier to build collaborative design relationship with strategic cooperation partners.

2) Establish information sharing mechanisms with key strategic partners. Sharing information of production planning, production information, inventory information, demand forecast information with key suppliers can reduce information distortion.

3) The supplier selection and management scope expand to supplier's supplier. Integration from the source of supply chain can ensure reliable raw materials, which can boost the competitiveness of suppliers and enhance the whole supply chain competitiveness.

4) Integration outsourcing service provider. Outsourcing service helps companies to use resources and capacity that they don't have. So the selection and integration of outsourcing service providers should be more emphasis on its core competence and the integration degree of supply chain, so that outsourcing service providers can better enhance the supply chain's competitive advantage and flexibility.

3. Customer integration: Customer integration includes enterprises in the entire distribution chain node (wholesalers, distributors, retailers and ultimately customers) integration. Selection of various vendors according to established evaluation index is to expand the sales network, optimize the distribution chain structure to reach distribution chain's labor clear (including the sale of product categories, covering the area, etc.). Three main aspects are for clients to integrate [8].

1) To provide management and technical support for the distributor, to establish a unified application system to real-time master distributor sales information; to form a strategic alliance with dealers to design distribution channels.

2) To establish partnerships with major customers to provide personalized products and services; to establish an effective customer feedback mechanism to keep abreast of 
changing customer needs and requirements; to share market information, sales information, demand forecast information, inventory information, production planning information with major customers.

3) To reduce the level of distribution channels, combining retail channels of distribution and online. Online sales are an important sales channel development trends, which can save investment costs.

\subsection{Planning and Control Layer Integration - Process Integration}

Supply Chain business process is an independent design, which is lack of effective convergence and required to integrate accordingly, such as the sale of a business process is another company's procurement process [9]. Based on all aspects of supply chain business process optimization among the basic implementation strategy, the core processes should be optimized to improve the efficiency of the whole supply chain and value creation capabilities.

Process integration should be based on the process management idea, whose three levels are process specification, and process optimization and process Reengineering. The supply chain core processes has different expression form by different classification, where are expressed by logistics, information flow and cash flow.

In the operation of the supply chain, the process of manufacturing resource materials or products, finished in different position or performance over time is known as logistics; the information of the production and marketing performance for the material in three main areas of change and shift is known as information flows; the costs associated with material value-added data is known as cash flow.

1. Logistics Integration: Internal production and logistics integration can improve their ability to optimize the allocation of resources; supply chain logistics integration can enhance the use of external resources to gain competitive advantages. Logistics integration also can improve time response, gain competitive advantage. Logistics integration ultimate aim is to meet customer demand, gain the fastest way the lowest cost to deliver products and services to customers.

Internal logistics integration refers to the integration of enterprise procurement, distribution, manufacturing, logistics, to achieve the integrated operation of the system, and upstream suppliers and downstream customers connected. Supply chain logistics integration concerns integration of logistics operations group, the wider and deeper level to improve the operation of the logistics system performance. Integration of logistics includes two levels of integration, logistics information and logistics facilities [10].

1) Logistics Information Integration. Related logistics information system is a bridge in the transfer logistics information, whose related information systems include inventory management information systems, distribution systems, data exchange and transmission systems, electronic financial transactions systems, retail point-of-systems and so on. Effective integration of information systems can increase the interface function; improve information sharing and the logistics efficiency of the system.

2) Logistics facilities integration. Core enterprise should overall plan infrastructure of supply chain, to make full use of co-members' infrastructure, such as distribution centers and warehouses. The establishment of efficient supply chain distribution system can reduce duplication of investment and increase resource utilization. Channel design and network analysis, optimization of supply chain manufacturing plants, 
distribution centers, distribution centers, warehouses and other infrastructure facilities, location and number are to make the entire supply chain logistics system more rational.

2. Information Integration. Information integration is an important level of supply chain integration, which decides the success of supply chain integration. Core business should integrate internal information to make the full internal information sharing between the different functions of application, so that the different departments can in a timely manner, quickly and accurately respond to changes in the market coordination to meet customer needs.

Supply chain systems integration with internet on the basis of internal information can increase the visibility levels of whole supply chain information, forecast and plan production with suppliers, customers to achieve reasonable allocation of the supply chain resources, timely and effective from order to delivery. Information integration approach can be integrated by IT technology integration and the relationship between two channels.

3. Financial flows integration. Integration of financial flows mainly includes integration of each node's credit, payment, accounts, receivable accounts payable and other aspects. An effective corporate credit tracking system and a unified method of payment should be established to enhance the utilization rate of capital turnover. Supply chain logistics, financial flow, information flow are accompanied, which constitute the entire value stream as shown in Figure 2.

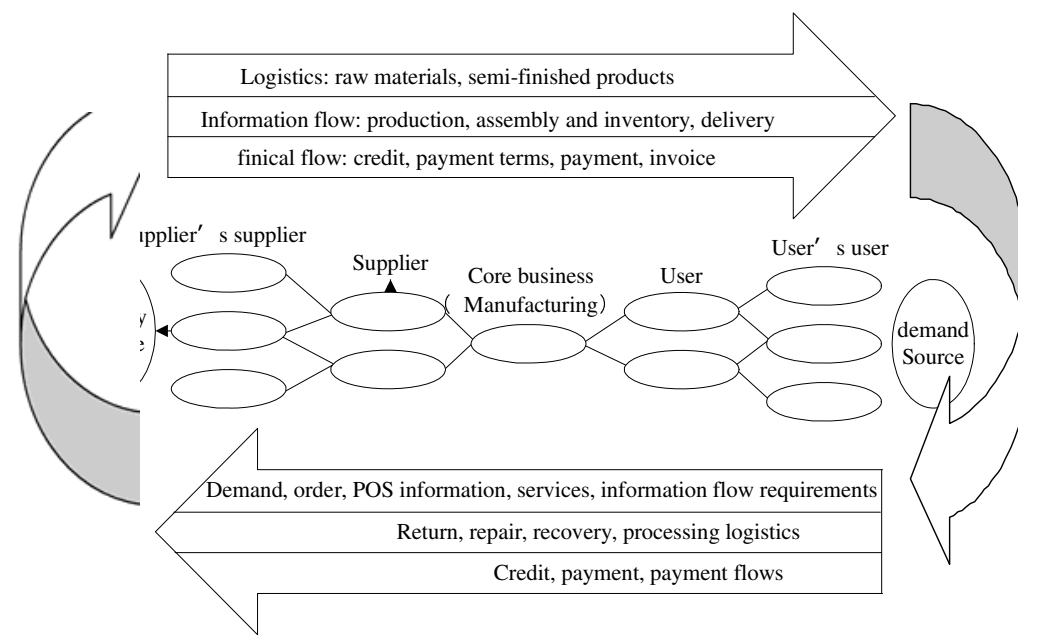

Fig. 2. The logistics, information flow and finical flow of supply chain

\subsection{Strategic Level Integration Cultural Integration}

Cultural integration is the highest level of supply chain integration, which can be divided into internal cultural integration and partner cultural integration. Within the enterprise, cultural integration should further highlight the characteristics of enterprises, namely the outstanding business value, business spirit, corporate style, business sense of service. The cultural integration of the supply chain is to create a 
unified culture, or each node integration between corporate culture and enhance supply chain cohesion and competitiveness. For the whole supply chain, cultural integration is mainly from the development strategy, ideas and management models.

\section{Conclusions}

This research based on the core manufacturer's supply chain management, with value-added process procurement, manufacturing and sales as line, provide reference model of supply chain integration and its implementation measures to integrate resource.

\section{References}

1. Adewole, A.: Developing a strategic framework for efficient and effective optimization of information in the supply chains of the UK clothing manufacturing industry; Supply Chain Management. An International Journal 10(5), 357-366 (2005)

2. Saad, M., Patel, B.: An investigation of supply chain performance measurement in the Indian automotive sector, Benchmarking. An International Journal 13(1/2), 36-53 (2006)

3. Petison, P., Johri, L.M.: Dynamics of the manufacturer - supplier relationships in emerging markets. Asia Pacific Journal of Marketing and Logistics 20(1), 76-96 (2008)

4. Lewis, I., Talalayevsky, A.: Improving the inter-organizational supply chain through optimization of information flows. The Journal of Enterprise Information Management 17(3), 229-237 (2004)

5. Fischer, A.: A global concept -Virtual companies. In: The Financial Times, July 16, p. 12 (1993)

6. Fawcett, S., Stanley, L., Smith, S.: Developing logistics capability to improve the performance of international operations. Journal of Business Logistics 18(2), 16-23 (1997)

7. Daugherty, P., Stank, T., Ellinger, A.: Leveraging logistics/distribution capabilities: the effect of logistics service on marketshare. Journal of Business Logistics 19(2), 35-51 (1998)

8. Nagurney, A., Dong, J., Zhang, D.A.: supply chain network equilibrium model. Transportation Research Part E: Logistics and Transportation Review 38(5), 281-303 (2002)

9. Chopra, S., Meindl, P.: Supply Chain Management: Strategy, Planning, and Operation. Prentice-Hall, Englewood Cliffs (2001)

10. Hao, M., Dröge, C., Stank, T.: The effect of logistics capabilities on firm performance: customer-focused versus information-focused capabilities. Journal of Business Logistics 22(2), 91-103 (2001) 